\title{
Assessment of parental awareness about malocclusion in Shiraz, Islamic Republic of Iran
}

\author{
S. Momeni Danaei, ${ }^{1}$ M. Oshagh, ${ }^{2}$ N. Pajuhi, ${ }^{3}$ Y. Ghahremani ${ }^{3}$ and S. Ghodsi Bushehri ${ }^{3}$
}

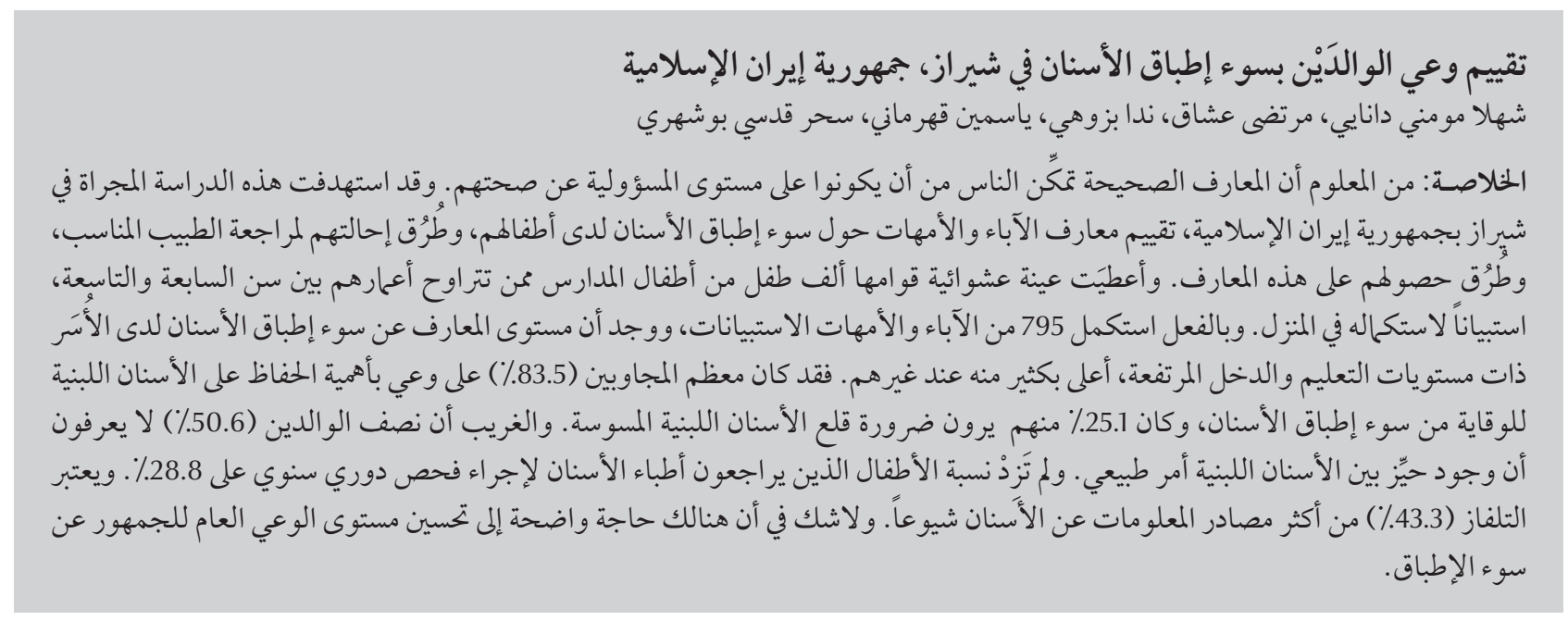

ABSTRACT Information empowers people to take charge of their health. The aim of this study in Shiraz, Islamic Republic of Iran was to evaluate parents' knowledge about dental malocclusion, referral routes and information sources. A random sample of 1000 7-9-year-old schoolchildren were given a questionnaire to complete at home. Questionnaires were completed by 795 parents. Knowledge about malocclusion was significantly greater in families with higher levels of education and income. Most respondents (83.5\%) were aware of the importance of maintaining primary teeth to prevent malocclusion, and $25.1 \%$ thought that carious primary teeth must be extracted. Half of the parents (50.6\%) did not know that spaces between primary teeth are normal. Only 28.8\% of the children visited dentists for annual routine check-ups. Television (43.3\%) was the most common source of dental information. The level of general public awareness about malocclusion needs to be improved.

\section{Évaluation des connaissances des parents concernant la malocclusion à Chiraz (République islamique d'Iran)}

RÉSUMÉ L'information rend les personnes autonomes dans la prise en charge de leur santé. L'objectif de la présente étude conduite à Chiraz (République islamique d'Iran) était d'évaluer les connaissances des parents concernant la malocclusion dentaire, les voies d'orientation-recours et les sources d'information. Dans un échantillon sélectionné aléatoirement, 1000 écoliers âgés de sept à neuf ans ont reçu un questionnaire à remplir à la maison. Sur ce total, 795 ont été remplis par les parents. Les connaissances concernant la malocclusion étaient plus importantes dans les familles où le niveau d'études et de revenu était supérieur. La plupart des répondants $(83,5 \%)$ connaissaient l'importance du maintien des dents temporaires afin de prévenir la malocclusion, et 25,1\% savaient que les dents temporaires cariées devaient être extraites. La moitié des parents (50,6 \%) ignorait que les espaces entre les dents temporaires étaient normaux. Seuls 28,8 \% des enfants se rendaient chez le dentiste pour des examens annuels de routine. La télévision était la principale source d'information (43,3 \%) dans le domaine dentaire. Le niveau de connaissances de la population concernant la malocclusion doit être amélioré.

${ }^{7}$ Shiraz Educational Research and Developmental Centre; ${ }^{2}$ Shiraz Orthodontic Research Centre and Department of Orthodontics, Faculty of Dentistry, Shiraz University of Medical Sciences, Shiraz, Islamic Republic of Iran (Correspondence to M. Oshagh: morteza_oshagh@yahoo.com). ${ }^{3}$ Faculty of Dentistry, Shiraz University of Medical Sciences, Shiraz, Islamic Republic of Iran.

Received: 22/07/09; accepted: 07/09/09 


\section{Introduction}

The focus in dentistry is shifting to prevention of disease rather than treatment and repair of damage, and the public's role has changed from passive recipient to participant in prevention. Helping individuals to preserve their oral health is an important goal which cannot be achieved without public information, education and motivation $[1-4]$. Better information generally motivates people to take charge of their health and treatment [5].

Almost every orthodontist has experienced misunderstandings with patients about treatment of malocclusion [6]. Bishop et al. recommended that patients who have a good knowledge of their disease or procedure have a better outcome than those who do not [7]. Although compliance with orthodontic treatments is dependant on various factors, the importance of knowledge should not be ignored, since lack of information may affect compliance [8]. Ley stated that providing patients with greater information generally causes increased compliance with treatment recommendations [9].

Habibian et al. found that schoolchildren wanted to know about the aetiology of malocclusion, why orthodontic treatment was carried out and when was the right time to start treatment [8]. The importance of information and its effect on cooperation were also identified by Brattstrom et al., who reported that the reasons for prematurely terminated treatments included insufficient information about the exact nature of treatment, lack of motivation and lack of communication between orthodontist and patient [10]. Nanda and Kierl also found that successful orthodontic treatment depended not only on the knowledge and skills of the clinician, but also on the cooperation of the patient and parents [11].

Although an orthodontist may suggest that a child needs orthodontic treatment, the parents' awareness that the child has an orthodontic problem will play a part in whether the child receives treatment. However, perceptions of orthodontic treatment need are multifactorial and are influenced by elements other than indices of normative orthodontic treatment needs [12]. A need for improved health education about orthodontic problems has been clearly indicated [13], but to improve public information about malocclusion we must first determine the present level of knowledge and sources of information. The purpose of this study in Shiraz, Islamic Republic of Iran was to evaluate knowledge about malocclusion among the parents of 7-9-year-old children.

\section{Methods}

\section{Sample}

The sample comprised 1000 schoolchildren aged 7-9 years old attending schools that were selected by random cluster sampling from 4 educational districts in the city of Shiraz. The criteria for inclusion were Farsi as their first language and no previous use of an orthodontic appliance [14]. Students accepted for orthodontic treatment were excluded because they were likely to receive different information that might have influenced the results. Ethical approval was obtained from the Ethics Committee of Shiraz University of Medical Sciences.

\section{Data collection}

A questionnaire to assess parents' knowledge about malocclusion was specially designed for this study by 2 expert orthodontists. The questions were divided into 3 major domains: general knowledge about malocclusion (whether they believe that taking care of primary teeth has an effect on dentofacial malocclusion); referral routes for routine checkups (where to go to check their child's dentofacial malocclusions such as prognathism and retrognathism of the jaws); and information sources about oral health (radio, television or mass media, friends, etc.). There were 13 questions with a closed response format that allowed subjects to choose from a fixed number of alternatives. The questionnaire was designed using simple language to be easy understood by parents. The questionnaire was scored to record a mean score for each of the 3 sections and a total score. If a parent answered all the questions correctly, in the sections for parents' awareness and referral routes, the maximum possible scores were 27 and 8 respectively. The scores were weighted so that the highest possible total score for knowledge about malocclusion was 35 . The data about information sources by parents was calculated separately. We also recorded demographic data for age, sex, ethnicity and family income, parents' occupation and parents' educationallevel (as a proxy measure for social class). The reliability of the questionnaire was measured by pretesting the instrument on a group of 20 people before it was used for the final research (Cronbach $\alpha=0.75$ ).

The questionnaires were brought to the schools by researchers and given to the teachers, who distributed them to students who satisfied the inclusion criteria with instructions that it was to be filled out at home. The respondents were instructed to answer as many of the questions as they could and to leave blank any that they were unable to complete. The parent or guardian answered the questions and the children returned the completed questionnaires to their teacher.

\section{Data analysis}

The mean score for each group of questions and mean total score for each questionnaire were compared. All data were analysed by analysis of variance, chi-squared tests and $t$-tests.

About $80 \%$ of the parents (795/1000) returned the questionnaires; $56.5 \%$ were the parents of boys and $43.5 \%$ of girls. The mean total knowledge score was 15.6 (SD 5.3) out of maximum score of 35 (Table 
1). Mean score for parents' awareness about malocclusion was 11.6 (SD 4.7) out of 27 and for knowledge about referral routes was 4.1 (SD 1.6) out of 8 .

There was a significant difference in the mean total knowledge scores between different educational districts of the city $(P<0.001)$ (Table 2$)$. Higher levels of education of the parents were associated with higher scores in the questionnaire $(P<0.001)$. Total scores also differed significantly depending on the father's employment. Families with higher incomes also scored significantly higher than those with lower incomes $(P<0.001)$. Those employed in public administration as a civil servant and in the private sector had significantly higher knowledge about malocclusion than those who were retired, employed as an unskilled (or manual) worker or unemployed $(P<0.001)$.

\section{General knowledge about dental problems and malocclusion}

Few parents (12.3\%) knew how to identify dental caries in their child's mouth by observation of discolouration, sensitivity or pain; $74.9 \%$ of parents had knowledge that caries of primary teeth must be restored but $25.1 \%$ thought that a carious primary tooth must be extracted or not be treated; $50.6 \%$ of parents did not know that spaces between primary teeth are a normal characteristic.

Concerning malocclusion, most respondents (83.5\%) knew the importance of maintaining primary teeth to prevent malocclusion, but $22.6 \%$ of them had no information about the time sequence of primary tooth exfoliation. Of the parents $25.4 \%$ did not know that oral habits (such as thumb-sucking, pacifier-sucking, pen-biting, nail-biting and lip-biting) can cause malocclusion. Also fewer parents (28.8\% and $47.2 \%$ ) were aware about the normal amount of overbite and overjet respectively. A majority of parents (80\%) were aware that malocclusion can adversely affect their child's appearance.

\begin{tabular}{lc}
\hline $\begin{array}{l}\text { Table } 1 \text { Parents' general awareness about orthodontic problems and knowledge } \\
\text { about referral to an orthodontist }(\boldsymbol{n}=\mathbf{7 9 5})\end{array}$ \\
\hline Variable & Mean score (SD) \\
Awareness about orthodontic problems (max. score 27) & $11.6(4.7)$ \\
Knowledge about referral to orthodontist (max. score 8) & $4.1(1.6)$ \\
Total knowledge (max. score 35) & $15.6(5.3)$ \\
\hline
\end{tabular}

$S D=$ standard deviation .

\section{Knowledge about referral route to dentist for routine check-ups}

Few parents (28.8\%) took their child to a dentist for annual routine check-ups and only $6.7 \%$ did not know where to take their children to check for malocclusion. Only 34.2\% of parents knew the appropriate age for first examining a child for malocclusion.

\section{Information sources}

Of the 795 parents who responded, $43.3 \%$ said they got their information from television, $13.1 \%$ from radio, $29.2 \%$ newspapers and magazines, $25.5 \%$ teachers and $40.5 \%$ from others sources such as the Internet and friends. Thus

\begin{tabular}{lcc}
\hline $\begin{array}{l}\text { Table } 2 \text { Parent's knowledge about malocclusion by parent's education, family } \\
\text { income and district of Shiraz }\end{array}$ & $\begin{array}{c}\text { Total knowledge } \\
\text { (max. score 35) }\end{array}$ & P-value \\
\hline $\begin{array}{l}\text { Variable } \\
\text { Mean score (SD) }\end{array}$ & $<0.001$ \\
Father's educational level & $12.9(4.4)$ & \\
High school & $15.4(4.6)$ & \\
Diploma & $19.1(5.1)$ & $<0.001$ \\
Above diploma & & \\
Mother's educational level & $12.9(4.5)$ & \\
High school & $15.5(4.5)$ & \\
Diploma & $19.5(5.0)$ & \\
Above diploma & & \\
Family income (million rials per month) & $13.3(4.6)$ & \\
$<2$ & $14.5(4.6)$ & \\
$2-3.5$ & $17.0(4.9)$ & \\
$3.5-5$ & $19.3(5.3)$ & \\
$>5$ & 12.001 & \\
Educational district & $13.4(4.3)$ & \\
1 (west and south-west) & & \\
2 (north and north-west) & & \\
3 (east and north-east) & & \\
4 (south and south-east) & & \\
\hline
\end{tabular}

television was the strongest medium for obtaining dental information.

\section{Discussion}

In this study about $20 \%$ of children's parents did not return questionnaires and a higher proportion of parents of boys than girls responded. This finding contrasts with Pietilä and Pietilä's study in Finland in which a higher percentage of families with girls returned the questionnaire [15], and it contradicts the common preconception that good appearance among girls is regarded as more important [16]. Contraryfindings,
$S D=$ standard deviation . 
however, were reported by Howitt et al. [17] and Horowitz et al. [18].

The children studied were selected from schools in different areas of the city of Shiraz to obtain a socioeconomic spread and there was a significant difference in knowledge of parents about malocclusions in different areas of the city which reflect differences in socioeconomic status. A higher level of parents' education or higher income was associated with higher knowledgescores about malocclusion. In a Finnish study, social class had no effect on the proportion of children needing or receiving orthodontic treatment [19], whereas in Norway Sivertsen found a higher need and demand for orthodontic treatment among higher social groups [20]. Reichmuth et al. also found that both socioeconomic status and ethnicity had an effect on desire for treatment [21]. Although knowledge about malocclusion affects perceived orthodontic treatment need, actual treatment needs and demand may be different.

The age range of students chosen for this study was $7-9$ years. This is the age at which the first orthodontist appointment is recommended. However, only onethird of parents knew the appropriate age for first examination of their children for malocclusion. In Pietilä and Pietilä's study most parents thought $7-8$ years was the best age for starting orthodontic treatment [15]. In Habibian et al.'s study one of the most common questions to schoolchildren about orthodontics was the right time to start treatment. It is therefore necessary to inform people about this topic [8]. In our study only the parents' opinions were asked, because we believed that 7-9 year old children were too young to assess their awareness of this issue [15]. Although it seemed appropriate to approach both the child and the parent, according to Horowitz et al. children do not have the ability to frame their own opinion in this respect until the age of around 10-12 years [18].

Our findings are unlikely to be the result of experimental bias because the schools were selected by random cluster sampling from 4 different districts of Shiraz city. Also the person responsible for data analysis was blinded to the study to minimize any bias that might arise from knowledge of the participants. To further reduce bias, researchers were instructed not to give verbal information about malocclusions and/or orthodontic treatments to students before and during the study. This ensured that, as far as possible, information came from only family knowledge.

There were obviously some limitations to the study. Our instructions were that questionnaires be completed by the family and it cannot be assumed that the questionnaires were completed by them alone, without help from others and the relevant literature [22]. Although in this study we did not ask about history of treatment in the family, Reichmuth et al.'s study found that children whose parents and siblings had previously undergone orthodontic treatment were more realistic and less likely to choose perfect occlusion as the ideal [21]. More mothers responded to the questionnaire in Dorsey's study [23] but in our study we did not analyse which member of the family responded.

Variations in educational level of the participants might also have an effect on parents' answers [22,24]. Thus, our questionnaire used simple language and was designed to be easy to understand for participants of different socioeconomic levels. Harwood et al. found that all 14year-old children could understand the word "orthodontics" but only $14 \%$ knew the meaning of the word "appliance" which was used widely in leaflets. The term "brace" could easily be substituted and may be more easily understood [25]. The actual reading ability of some individuals is even lower than the level of education completed $[1,3,14]$.

This study showed that television was the most common source of dental information. However Edward et al. reported that newspapers, magazines and direct mail advertisements were viewed more favourably than radio, television and billboard advertisements [26]. This difference may be attributed to the fact that their study evaluated media advertising effects on consumer perceptions of orthodontic treatment quality.

Our study showed that less than one-third of parents took their children to the dentist for annual routine checkups. In a dental care system where children visit their dentist regularly and dentists work in cooperation with an orthodontist, parents' awareness of orthodontic problems agrees fairly well with the orthodontist's assessment of treatment need [15]. Hirst reported that a high proportion of parents (70\%) knew that their child should continue to see the dentist for routine care during orthodontic treatment [13]; the difference may be attributed to differences in the cultural setting and study design.

In this study most parents knew the importance of maintaining primary teeth in the development of malocclusions but about one-quarter of them did not have any information about the time sequence of primary tooth exfoliation. One-quarter of parents did not know the role of oral habits in the development of malocclusion and a similar proportion thought that a carious primary tooth must be extracted or not treated. Half of families did not know that spacing of primary dentition is a normal characteristic and most parents did not have information about normal overbite. A high proportion of parents (80\%) were aware that malocclusion adversely affect their child's appearance. This is comparable to Mugonzibwa et al.'s study which found that most children (85\%) recognized well-aligned teeth as important for overall facial appearance [27].

In conclusion, or results suggest that general public information about malocclusion needs to be improved. Others have suggested that parents need to informed about orthodontic treatments, length of treatments [13], the alternatives available and the risks and benefits of treatments [25], 
factors which may influence desire and demand for treatment [28 29] and produce a shift in their attitudes [30]. Information leaflets which are cheap to produce can increase the public's knowledge about malocclusion [31]. For communication to be effective, the message must be understood and remembered, and so future research should focus on methods of improving communication with lay people and patients $[32,33]$.

\section{Acknowledgements}

This study was supported by the Office of the Vice Chancellor for Research of Shiraz University of Medical Sciences.

We thank the Center for Development of Clinical Research of Nemazee Hospital in Shiraz for editorial assistance, and K. Shashok (AuthorAID in the Eastern Mediterranean) for improving the use of English in the manuscript.

\section{References}

1. Bakdash MB, Odman PA, Lange AL. Distribution and readability of periodontal health education literature. Journal of Periodontology, 1983, 54:538-541.

2. Bakdash MB. Patient motivation and education: a conceptual model. Clinical Preventive Dentistry, 1979, 1:10-14.

3. Bakdash MB, Keenan KM. An evaluation of the effectiveness of community preventive periodontal education. Journal of Periodontology, 1978, 49:362-366.

4. Scholle RH. The final barrier. Journal of the American Dental Association, 1980, 101:740.

5. Bunton K, Macdonald K. Health promotion disciplines and diversity. London, Routledge; 1992:69-70.

6. Starnes LO. Patient brochure for two-phase treatment. Journal of Clinical Orthodontics, 1991, 25:503-504.

7. Bishop $\mathrm{P}$ et al. Reflections on a multidisciplinary approach to evaluation of patient literature materials. Health Education Journal, 1997, 56:404-413.

8. Habibian M, Gelbier S, Munday BA. Perceived information needs in respect of orthodontics amongst 11-12-year-old girls: a study through health visitor sessions in schools. International Journal of Paediatric Dentistry, 2003, 13:348-355.

9. Ley P. Communicating with patients. London, Chapman and Hall, 1988: 172-179.

10. Brattström V, Ingelsson M, Aberg E. Treatment co-operation in orthodontic patients. British Journal of Orthodontics, 1991, 18:37-42.

11. Nanda RS, Kierl MJ. Prediction of cooperation in orthodontic treatment. American Journal of Orthodontics and Dentofacial Orthopedics, 1992, 102:15-21.

12. Hamdan AM. The relationship between patient, parent and clinician perceived need and normative orthodontic treatment need. European Journal of Orthodontics, 2004, 26:265-271.

13. Hirst L. Awareness and knowledge of orthodontics. British Dental Journal, 1990, 168:485-486.

14. Thickett E, Newton JT. Using written material to support recall of orthodontic information: a comparison of three methods. Angle Orthodontist, 2006, 76:243-250.

15. Pietilä T, Pietilä I. Parents' views on their own child's dentition compared with an orthodontist's assessment. European Journal of Orthodontics, 1994, 16:309-316.

16. Baldwin DC. Appearance and aesthetics in oral health. Community Dentistry and Oral Epidemiology, 1980, 8:244-256.

17. Howitt JW, Stricker G, Henderson R. Eastman esthetic index. New York State Dental Journal, 1967, 33:215-220.

18. Horowitz HS, Cohen LK, Doyle J. Occlusal relations in children in an optimally fluoridated community. IV. Clinical and social-psychological findings. Angle Orthodontist, 1971, 41:189-201.
19. Milen A et al. Dental health status, habits and care of Finnish children and youths in 1981-82. A feasibility study of an information system. Finland, Helsinki, Health Services Research by the National Board of Health, 1986.

20. Sivertsen R. How different social classes benefit from the subsidized orthodontic services in Norway. European Journal of Orthodontics, 1981, 3:273-277.

21. Reichmuth $\mathrm{M}$ et al. Occlusal perceptions of children seeking orthodontic treatment: impact of ethnicity and socioeconomic status. American Journal of Orthodontics and Dentofacial Orthopedics, 2005, 128:575-582.

22. Patel JH, Moles DR, Cunningham SJ. Factors affecting information retention in orthodontic patients. American Journal of Orthodontics and Dentofacial Orthopedics, 2008, 133(Suppl.):S61-S67.

23. Dorsey J, Korabick K. Social and psychological motivations for orthodontic treatment. American Journal of Orthodontics, 1977, 72:211-215.

24. Rud B, Kisling E. The influence of mental development on children's acceptance of dental treatment. Scandinavian Journal of Dental Research, 1973, 81:343-352.

25. Harwood A, Harrison JE. How readable are orthodontic patient information leaflets? Journal of Orthodontics, 2004, 31:210-219

26. Edward DT et al. Media advertising effects on consumer perception of orthodontic treatment quality. Angle Orthodontist, 2006, 78:771-777.

27. Tulloch JF et al. A comparison of attitudes toward orthodontic treatment in British and American communities. American Journal of Orthodontics, 1984, 85:253-259.

28. Mugonzibwa EA et al. Perceptions of dental attractiveness and orthodontic treatment need among Tanzanian children. American Journal of Orthodontics and Dentofacial Orthopedics, 2004, 125(4):426-433.

29. Gravely JF. A study of need and demand for orthodontic treatment in two contrasting National Health Service regions. British Journal of Orthodontics, 1990, 17:287-292.

30. Espeland LV, Ivarsson K, Stenvik A. A new Norwegian index of orthodontic treatment need related to orthodontic concern among 11-year-olds and their parents. Community Dentistry and Oral Epidemiology, 1992, 20:274-279.

31. Ormrod J, Robinson $M$. How readable are health education leaflets? Health Visitor, 1994, 67:424-425.

32. Mortensen MG, Kiyak HA, Omnell L. Patient and parent understanding of informed consent in orthodontics. American Journal of Orthodontics and Dentofacial Orthopedics, 2003, 124:541-550.

33. Ley $\mathrm{P}$, Spelman MS. Communicating with the patient. London, Staples Press, 1967:114-116. 